\begin{tabular}{c} 
International Journal of Engineering \& Technology, $7(x)(2018) 427-432$ \\
International Journal of Engineering \& Technology \\
Website: $\begin{array}{c}\text { www.sciencepubco.com/index.php/IJET } \\
\text { doi: } 10.14419 / \text { ijet.v7i2.9995 } \\
\text { Research paper }\end{array}$ \\
\hline
\end{tabular}

\title{
Analysis of transformer less inverter for PV applications
}

\author{
Selvamathi. $\mathbf{R}^{1 *}$, V. Indragandhi ${ }^{2}$, AshokKumar. $\mathrm{L}^{3}$ \\ ${ }^{1}$ Research Scholar, Vellore Institute of Technology, Vellore \\ ${ }^{2}$ Associate Professor, Vellore Institute of Technology, Vellore \\ ${ }^{3}$ Professor, PSG College of Technology, Coimbatore \\ *Corresponding author E-mail: selvamthir@gmail.com
}

\begin{abstract}
To enhance the effectiveness and decrease the cost of a Photovoltaic (PV) system, the utilization of transformer less PV inverters is an option of expanding interest. In any case, this topology should be considered in detail, as it shows a few issues like effectiveness degradation and safety issues identified with the galvanic association between the system and the PV generator.

In this research paper, a review of standalone and grid-connected PV inverter structures has been done. From one viewpoint, a few options in light of established structures have been introduced. At last parasitic capacitance in PV arrays and leakage current produced from PV systems are examined.
\end{abstract}

Keywords: Photovoltaic; Transformer Less Inverters; Grid Connected Systems; Leakage Current; Parasitic Capacitance.

\section{Introduction}

The improvement of recent energy sources is constantly upgraded as a result of the basic circumstance of the chemical industrial fuels, for example, oil, gas and others. In this manner, the sustainable power sources have turned into a more vital supporter of the aggregate energy expended on the globe. Truth be told, the interest for sun based vitality has expanded by $20 \%$ to $25 \%$ in the course of recent years [1]. The marketplace for PV systems is becoming around the world.

Total installed Renewable Energy Sources (RES) capacity India is shown in Fig.1. PV is presently, after hydro and wind control, the third most imperative sustainable power source as far as all around introduced limit. The development rate of PV amid 2013 came to very nearly $70 \%$, a remarkable level among every renewable innovation.

The 80 billion kWh energy yield is adequate to cover the yearly power supply needs of more than 20 million family units on the globe with a specific end goal to get advantage from the uses of PV systems, explore exercises are being led trying to increase advance change in their cost and effectiveness. There are numerous kinds of sustainable power sources, for example, wind, hydroelectric and a standout amongst the most famous is the energy from sun.

Fig. 2 demonstrates the consequence of a worldwide energy office learn about the world's energy utilization. Today, the sun oriented energy covers just $0.5 \%$ of the world's power utilization, however will end up a standout amongst the most imperative sustainable power sources later on. In 2050, it has been evaluated that (3060) Terawatt power every year being required and nearby solar system is the greatest supporter.

The requirement for a cleaner domain and the constant increment in vitality needs makes decentralized sustainable power source creation more vital. This ceaselessly expanding power utilization over-burdens the distribution grids and in addition the power stations, consequently negatively affecting force accessibility, safety and excellence. One of the answers for beating this is the Distributed Generation (DG). DG's are utilizing sustainable power sources like sunlight based, wind or hydro have the preferred standpoint that the power is delivered in closeness to where it is expended.

In recent years solar technologies have seen a precipitous reduction in costs and a dramatic rise in operative efficacy. Solar power has become the go to solution for those looking for clean and environmentally friendly sources of energy, as well as a viable alternative to fossil fuels and nuclear. The chief advantage of Photovoltaic technologies is the simplicity of their design. By having no moving parts, PV equipment possesses a significantly long operative lifetime and require very little in terms of maintenance. Currently, PV panels find themselves used in all aspects of modern life; from aerospace industry applications to supplying energy to remote sites. PV panels are increasingly coming into contact with the general public as, more and more, public opinion shifts towards identifying viable sources of green energy. 


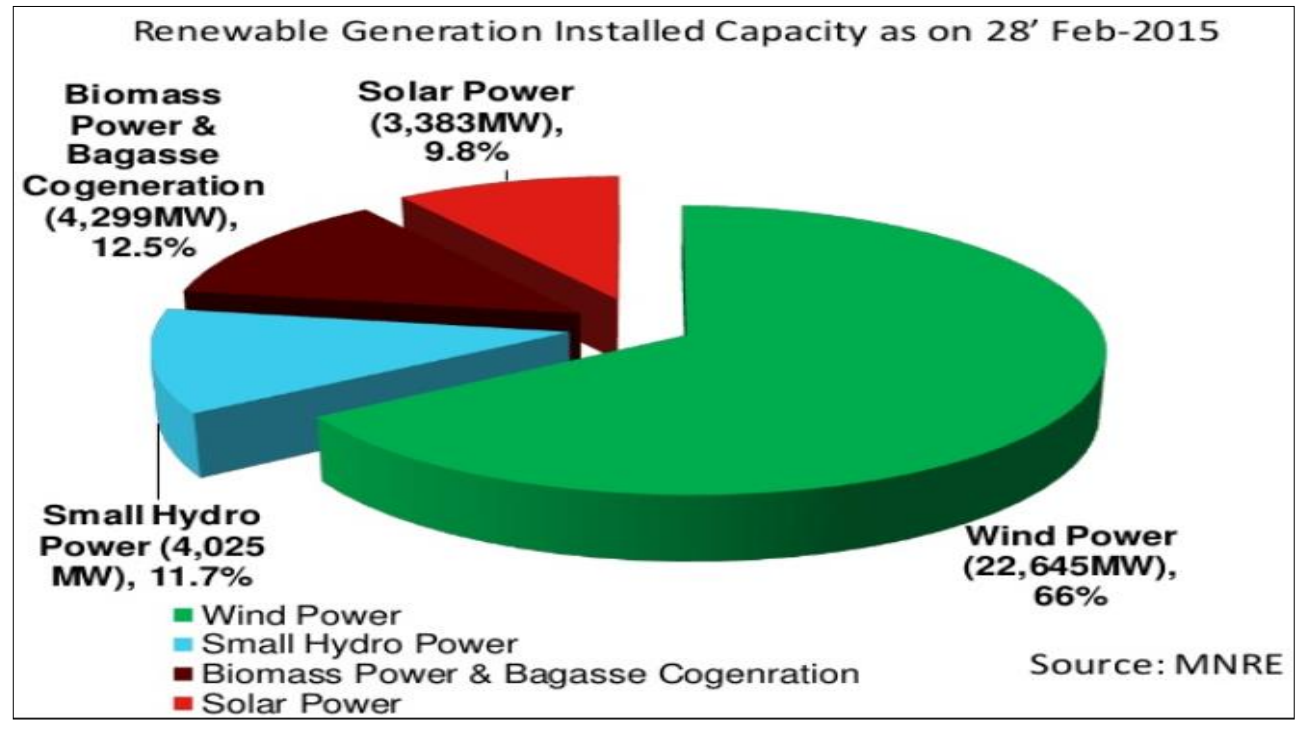

Fig. 1: Installed Power Capacity in India.

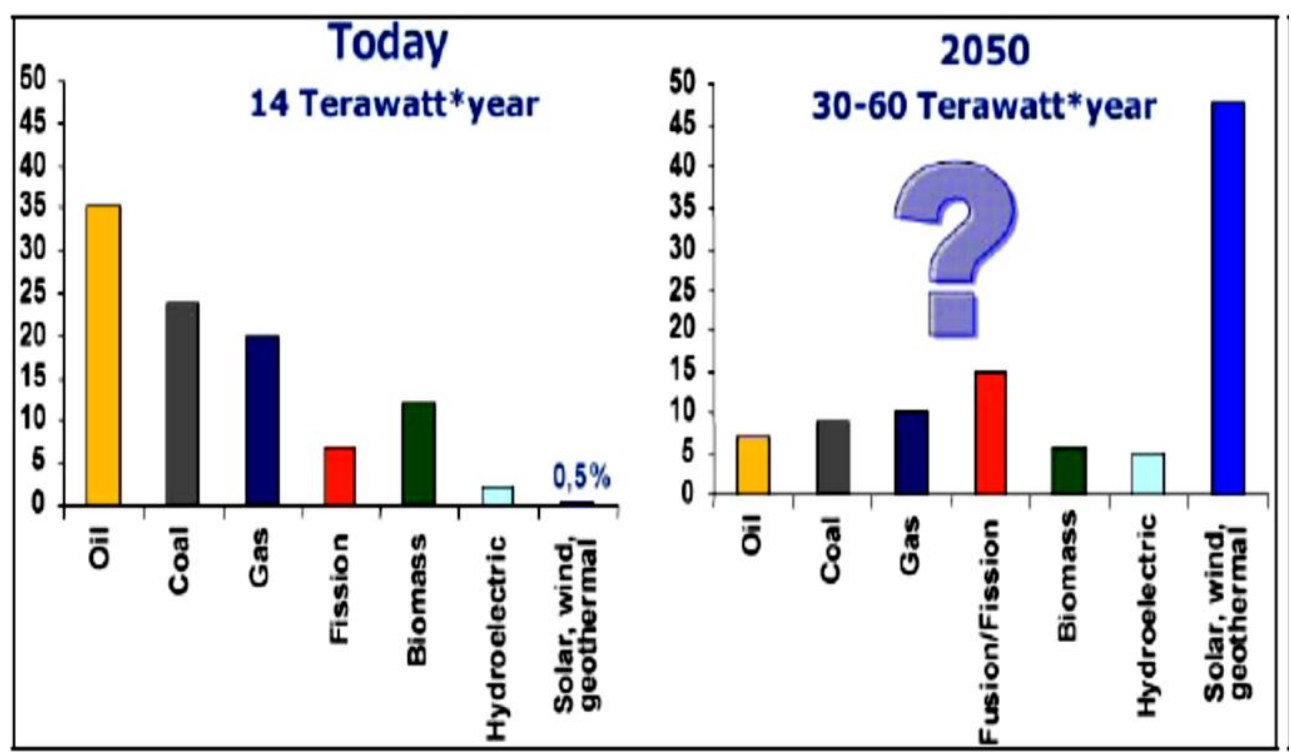

Fig. 2: The World's Energy Consumption.

\section{Stand-alone solar PV systems}

Stand-Alone systems are usually deployed in remote areas and in developing countries where the infrastructure does not have ready access to the local power grids. However, the cheap costs of production and deployment have allowed these remote area power supplies to be implemented in industrialized nations by people seeking innovative and cost effective methods to power traffic lighting, parking meters, and sewage processing. Usually, StandAlone systems are coupled with robust storage systems that allow for loads to be met even when sunlight is not readily available, such as early in the morning and at night.

\section{Grid-connected solar PV systems}

Grid connections allow for Photovoltaic units to be integrated into the local power grid and supply it with power. An inverter is integrated into the circuit which converts all DC power to AC power and ensures that proper voltage and frequency synchronicity is attained between the PV unit and the local distribution grid. Most notably, a working household PV system can be joined into the supply grid so that any excess energy leftover after supplying the house can be pumped directly into the local power circuit. The majority of these systems tend to be rather large with capacities that range above $100 \mathrm{~kW}$ but, more and more, smaller units with grid connection capabilities are coming into the public market. Generally, these types of units do not possess energy storage capabilities but there are a few configurations that make use of batteries to increase the efficacy of the PV unit; thereby incrementing energy availability to the system and providing backup functions in case of grid failure. These additional benefits help to offset the higher costs of said systems and encourage increased investment in order to spur competitiveness. As expected, grid connected PV systems take up the highest share of the installed capacity.

Most grid-connected PV units are designed with specific safety parameters in the way of galvanically isolated transformers. However, these units tend to be cumbersome in size and also reduce the overall efficiency of the photovoltaic capacity by up to six percent. In order to overcome these hurdles, some PV systems have been designed without the need for a transformer. These units are smaller, cheaper, and more efficient, and thus transformer-less configurations should be adopted in order to functionally improve the performance of single phase PV inverter systems. Some concerns regarding safety and current leakage have arisen, so more research should be conducted. Presently there are several models of transformer-less Photovoltaic inverters available on the market. It is recommended that a literature survey be conducted in order better to analyze the existing available options of operation. PV systems currently integrated into low voltage grids play an important role in distribution and generation systems. PV inverters should have the subsequent features: 
- Competitive costs

- Compact dimension in order to better accommodate domestic requirements

- Reliability of function

- Efficiency of output

- Proven safety

In recent years PV inverter technology has experienced a spur in innovation. From Fig. 3, we can observe that total costs have been reduced by about half in the last twenty years while efficiency and reliability have improved exponentially. The expected costs of PV inverter under $10 \mathrm{~kW}$ will range anywhere between 0.2 and 1.2 Euro/kW. Most of the photovoltaic innovation is currently occurring in Europe and America, which are using mostly small scale systems integrated into the local grids. In order to further improve the cost to efficiency ratio of Photovoltaic systems, new inverter designs are constantly being developed. Grid-connected PV inverters are [2], [3]:

i). Central Inverters

ii). String type Inverters

iii). Module Integrated-Inverters

iv). Multistring Inverters

\subsection{Central inverters}

Photovoltaic systems larger than $10 \mathrm{~kW}$, when arranged in parallel circuits, are connected to one central inverter as is shown in Fig. 3. (a). Initially, converters that relied on the line voltage of the AC system, or line commutated thyristors, were used for this purpose. This practice was replaced by the use of IGBT equipped force commutation inverters, based on their increased efficiency and lower production and maintenance costs.

However there are significant disadvantages to this new configuration:

- High voltage DC cable connections must be present between panels and inverter unit

- Power loss due to MPPT(Maximum Power Point Tracking) problems

- Power loss due to module divergence

- String diode failure

- Entire system relies on a single component

\subsection{String inverters}

(A)

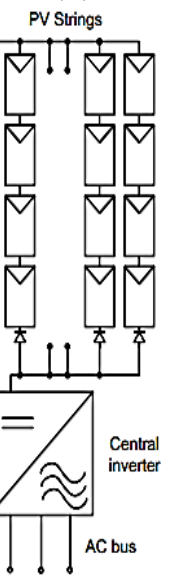

(B)

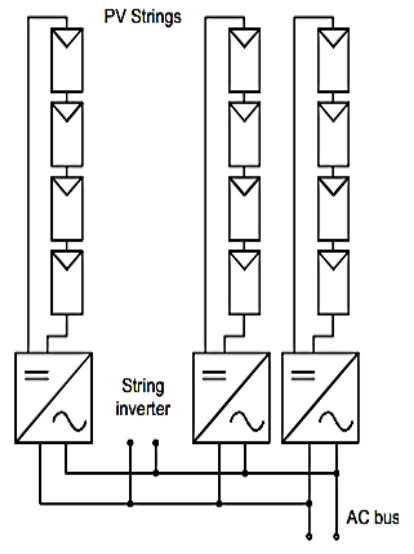

(C)

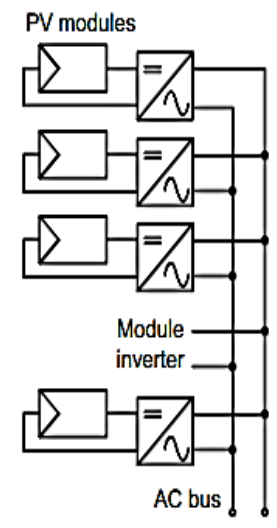

(D)

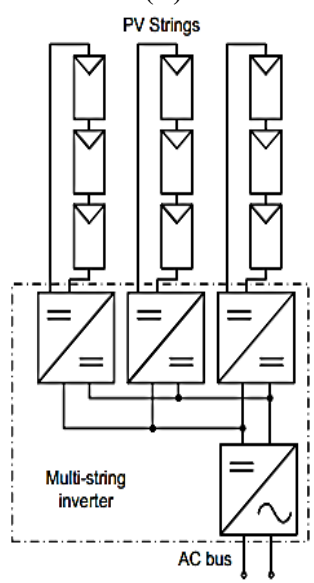

Fig. 3: Different Types of Grid-Connected PV Inverters A) Central Inverter. B) String Inverter. C) Module Inverter. D) Multistring Inverter.

\section{Analysis of grid connected inverters}

Whenever a Photovoltaic system is directly integrated into a local grid, it is expected that the power generated complies fully with detailed safety regulations, which are specified by the local utility
String inverters, shown in Fig. 3. (b) were first introduced into global markets in 1995. The string inverters are set in parallel and then integrated into the power grid. It is possible to set up these systems using fewer PV, but in that case a frequency transformer will most likely be needed for boosting purposes.

Compared to the Central Inverters, String Inverters present the following advantages:

- No diodes are needed within the String

- $\quad$ Distinct MPPT per each string

- Improved energy production

- Lower price

\subsection{Module inverters}

An AC module is normally composed of a singular panel connected directly to the grid through its own inverter as is shown in Fig. 3. (c). The advantage of this particular set up is the reduction of mismatch losses; this is mainly due to the fact that every panel has its own inverter and MPPT, thereby taking full advantage of the power production. Power yields are more optimized when compared to that of string inverters. These systems possess a sort of plug and play modality which allows for easier modification of the entire system when it is required. There is one important disadvantage to consider and that is the low overall effectiveness due to voltage amplifications, and the price per watt is still considerably higher than in other configurations. With increased rates of adoption, which will lead to increased manufacture of the components, these systems and their production costs will drop over time. [4].

\subsection{Multi string inverters}

Multi string inverters have recently come into prevalence on the photovoltaic market. Multistring configurations present an intermediate compromise between single string and module inverters By combining the strengths of both string and module inverters, as shown in Fig. 3.(d), multistring inverters are able to bypass many of the individual pitfalls that plague these other more common configurations. Multistring Inverters also place several DC-DC, converters each with MPPT capability, which feed energy to a central DC-AC inverter. In this manner, no matter the surrounding local conditions of the PV string, it can be successfully connected to one main grid-connected inverter [5]. regulating body. Some common international standards pertaining to grid-connected PV systems are:

- IEC 60364-7-712:2005 Electrical Installations of Buildings. Part 7: requirements for special installations or locations. Sec 712: Photovoltaic systems. 
- IEEE 1547.1-2005 IEEE Standard Conformance Test Procedures for Equipment Interconnecting Distributed Resources with Electric Power Systems.

- UL 1741 Standard for Safety Inverters, Converters, Controllers and Interconnection System Equipment for use with Distributed Energy Resources, 7th May 1999, updated in 2005.

- IEEE 929-2000. Recommended Practice for Utility Interface of solar PV Systems.

- IEC 61727 (1995-06) PV Systems - Characteristics of the Utility Interface.

- DS/EN 61000-3-2 (2001) EMC, Limits for Harmonic Emissions (equipment input current up to and including $16 \mathrm{~A}$ per phase)

- VDE-0126-1-1 (2006).

Most of these international regulations specified above are associated with total harmonic distortion levels and to the individual levels found in the injected current. Also regulated strictly are the frequency deviation between grid voltage the standard, the power factor, operating voltage ranges and the total DC current that will most likely be introduced into the system. In [4-5], a comparison of three different standards is made (IEC61727, IEEE1547 and EN61000-3-2), concentrating on the heretofore aforementioned matters.

Regarding DC current injection, Table.1 summarizes the requirements set by each standard [14-16]:

Table 1: Limit of the Injected DC Current for Different Standards

\begin{tabular}{|c|c|c|c|c|c|}
\hline & IEC61727 & $\begin{array}{l}\text { VDE- } \\
0126- \\
1-1 \\
\end{array}$ & IEEE1547 & $\begin{array}{l}\text { EN61000-3- } \\
2\end{array}$ & $\begin{array}{l}\text { IEEE } \\
929- \\
2000 \\
\end{array}$ \\
\hline $\begin{array}{l}\text { DC } \\
\text { current } \\
\text { Injection }\end{array}$ & $\begin{array}{l}<1 \% \text { of } \\
\text { rated } \\
\text { Output } \\
\text { side cur- } \\
\text { rent }\end{array}$ & $<1 \mathrm{~A}$ & $\begin{array}{l}<0.5 \% \text { of } \\
\text { rated } \\
\text { output side } \\
\text { current }\end{array}$ & $\begin{array}{l}<0.22 \mathrm{~A} \\
\text { corresponds } \\
\text { to a } 50 \mathrm{~W} \\
\text { rectifier }\end{array}$ & $\begin{array}{l}<0.5 \\
\% \text { of } \\
\text { rated } \\
\text { Output } \\
\text { side } \\
\text { current }\end{array}$ \\
\hline
\end{tabular}

Additionally, the VDE-0126-1-1 standard specifies that in the situation that a DC current is inserted into the grid, that is greater than 1 Ampere, a mandatory interruption of $0.2 \mathrm{~s}$ is required. No other standard makes mention of specific requirements for current stoppage times.

Only one regulation specifically mentions transformer-less Photovoltaic configurations concerning burden and outflow of current levels; that is the German VDE-0126-1-1.

According to the VDE-0126-1-1, there are three distinct currents that have to be carefully supervised:

- Those generated by ground faults. These currents can appear when an insulation failure manifests and current overflows through the ground wire.

- Direct fault currents, represented by the total sum of the instantaneous values of the main currents. Under normal operative conditions, the sum should be zero.

- Leakage ground current is mainly caused by parasitic capacitance.

Usually, monitoring for these specific faults is performed by a RCMU, or Residual Current Monitoring Unit. The RCMU measures both fault and leakage currents of the system in its entirety. The VDE-0126-1-1 regulation dictates that interruption is required within $0.3 \mathrm{~s}$ in case there is a leakage of current measuring more than $300 \mathrm{~mA}$. Leakage current jumps and their respective disconnection times [17], as detailed in Table .2.

Table 2: Leakage Current Jumps vs. Disconnection Times

\begin{tabular}{ll}
\hline Leakage Current Jump Rate (mA) & Disconnection Time (s) \\
\hline 30 & 0.3 \\
60 & 0.15 \\
100 & 0.04 \\
\hline
\end{tabular}

As shown in Table 2.2, anytime the root mean square value of the fault or leakage exceeds the minimum of $30 \mathrm{~mA}$, then a mandatory discontinuation of current is required within the specified time frame. This measure allows for the main system to be deenergized and damage minimized in case of an accident or grounding incident.

\section{Transformer-less $P V$ inverters}

Galvanic isolation is frequently provided by transformer. This transformer will have a significant effect on the efficacy of DC to $\mathrm{AC}$ conversion of any grid connected PV system [6]. The extent of any galvanic isolation in grid-integrated PV systems will hinge on entirely on the local safety guidelines. In some countries, like the United Kingdom and Italy, galvanic isolation is mandatory and is performed by low frequency step up transformers that are set up on the grid or by high frequency transformers placed on the DC side of the converter, as detailed in Figs. 4 and Fig. 5.

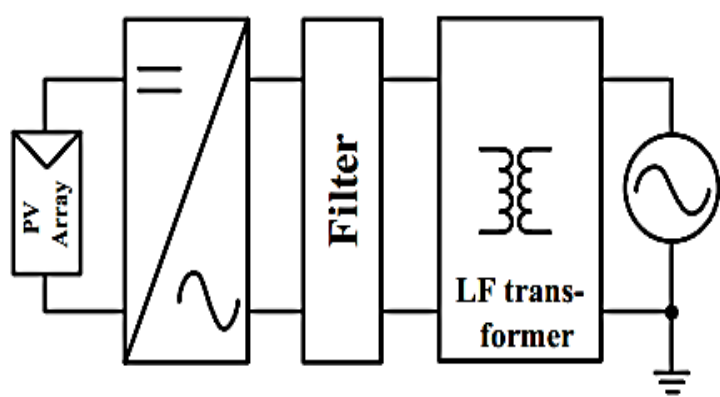

Fig. 4: Grid Side Low Frequency Transformer.

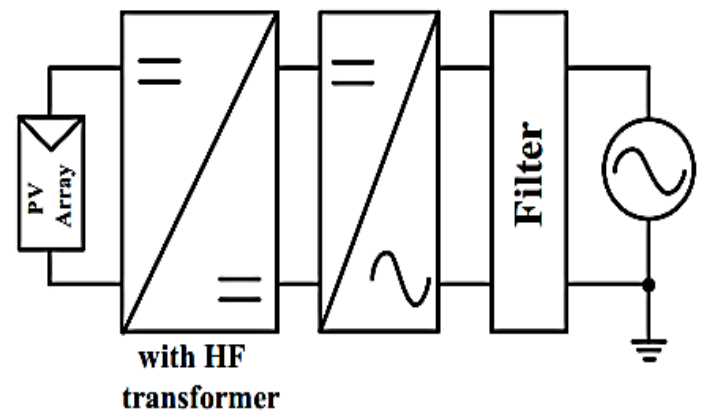

Fig. 5: DC Side High Frequency Transformer.

On the other hand, many countries which do not require any type of galvanic isolation whatsoever. In these cases other technological solutions are produced to isolate the Photovoltaic array from the main electrical lattice. It is pertinent to remember that transformer-less Photovoltaic configurations drastically reduce the cost and installation complexity of the whole system [18-19].

One drawback of transformer-less PV configurations is the possibility for DC currents to be injected into the AC current. This phenomenon can potentially saturate the magnetic components in the supply transformer, which can lead to overheating and eventual unit failure [7]. Photovoltaic inverters generally have two efficiencies which are reported by the manufacturer: Maximum Efficiency, or the highest DC-AC conversion rate, and a subjective efficacy reliant on the different solar irradiation levels. The so called European efficiency is based on the formula below [8]:

$\eta_{E U}=0.03 \eta_{5 \%}+0.06 \eta_{10 \%}+0.13 \eta_{20 \%}+0.1 \eta_{30 \%}+$ $0.48 \eta_{50 \%}+0.2 \eta_{100 \%}$

Fig.6. has been made with data compiled from a database of commercially available Photovoltaic inverters, presented in a respectable industry publication. [9], Here are listed many important and defining characteristics of the different inverter options available. Transformer-less inverters are represented by the dots $(0)$, while the stars $(*)$ represent the different topologies including a high frequency DC-DC transformer. Triangles $(\boldsymbol{\nabla})$ represent the 
inverters that possess a low frequency transformer implemented grid side, providing galvanic isolation between the Photovoltaic unit and general grid. It is made apparent that in the case of Photovoltaic configurations up to $6.5 \mathrm{~kW}$, transformer-less variants are capable of reaching maximum efficiencies while inverters with galvanic isolation have a diminished maximum conversion efficiency.
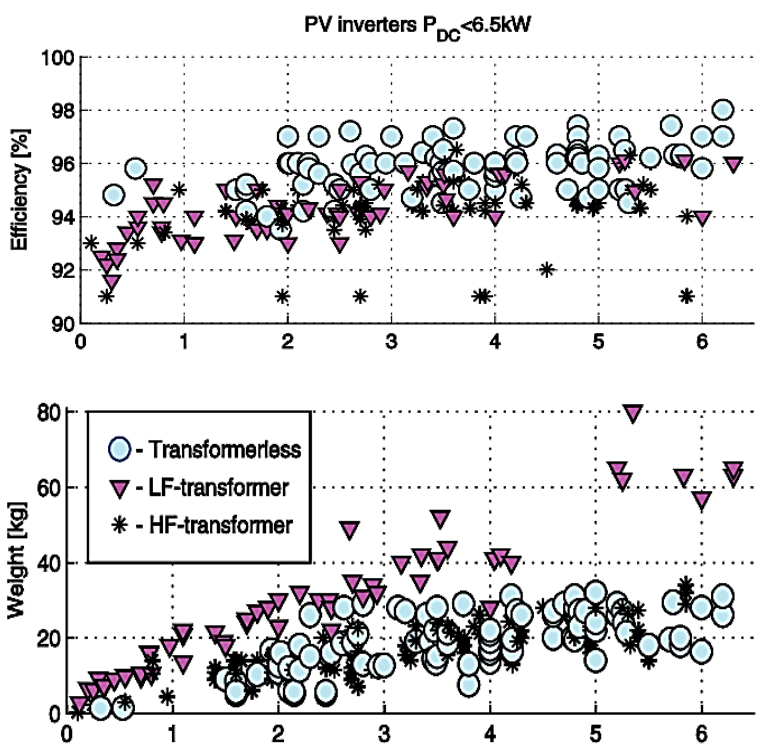

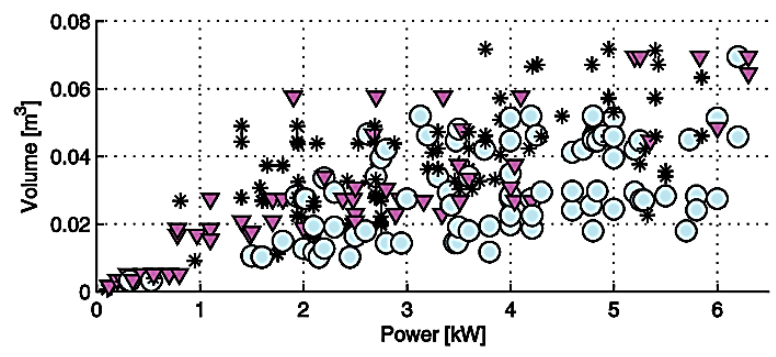

Fig. 6: PV Inverter Comparison Based on PHOTON Database.

It is made evident by the data and thus we can conclude that for the most part, that inverters with transformer-less configurations are able to provide a marked increase in efficiency, while offering the convenience of a smaller package size than units with galvanic separation protocols. In the case of Fig. 6, the purpose for restricting the power output up to $6.5 \mathrm{~kW}$ is the fact that there is a more limited offering of units between the ranges of $6.5 \mathrm{~kW}$ and $15 \mathrm{~kW}$ and their inclusion would have adversely skewed the reliability of the resulting data.

\section{Problems on PV systems}

\subsection{Parasitic capacitance of PV arrays}

Most modern offerings in the photovoltaic panel market will have a metallic frame; this is required in order to meet grounding regulations implemented by utility regulators across the markets. This presents a slight problem, as when combined with the panels' sizeable surface area, the metallic frame produces a parasitic capacitance, as shown in Fig. 7.

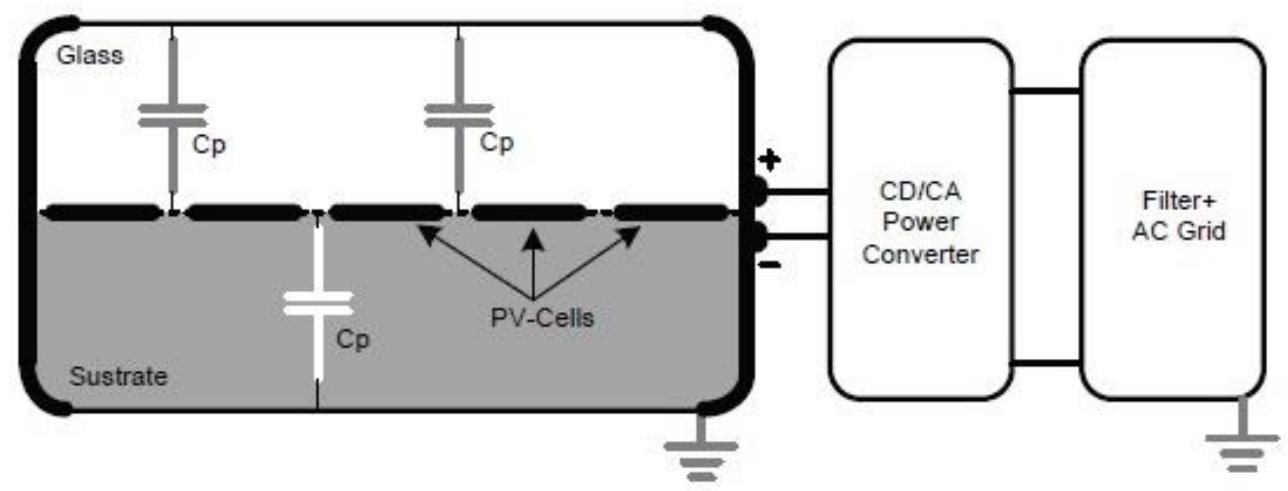

Fig. 7: Parasitic Capacitance in PV Panels.

The total value of the parasitic capacitance will hinge on:

- Total surface are of the Photovoltaic panel array and grounded frame

- The total distance of the Photovoltaic cell to the converter module

- Surrounding atmospheric circumstances which have an effect of conductivity of the system

Studies done on the subject have shown that parasitic capacitance of most Photovoltaic panels lie around $150 \mathrm{pF}$. It was also discovered that if the surface of the panel is wholly covered with water, the parasitic capacitance increased to $9 \mathrm{nF}$. According to the results the parasitic capacitance varies in a range that lays between $50 \mathrm{nF}$ and $150 \mathrm{nF}$ for each $\mathrm{kW}$ produced by the installed Photovoltaic array. Parasitic capacitance measurements have also been recorded for different PV panels, ranging from $100 \mathrm{pF}$ to $3.6 \mu \mathrm{F}$. One more finding of the study is that in thin film PV modules parasitic capacitance can attain values up to $1 \mu \mathrm{F} / \mathrm{kW}$; mostly in part because of the metallic finish of the sheets on which the components have been placed.

\subsection{Leakage ground current}

A transformer-less configuration lacks the important galvanic isolation between the Photovoltaic lattice and the power grid. The fluctuations continuously charge and discharge the parasitic capacitance that exists between the surface area of the PV frame and grounded structures, shown as $\mathrm{C}_{\mathrm{G}-\mathrm{PV}}$ in Fig. 8. The parasitic capacitance in conjunction with the DC lines that run from the Photovoltaic system to the attached inverter unit, create a certain resonance circuit, whose frequency depends almost entirely on the size of the PV arrangement and the length of the cables that compose the circuit [10]. 


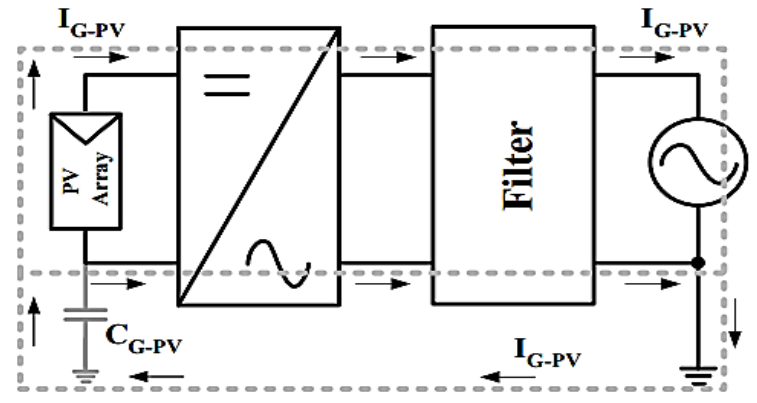

Fig. 8: Ground Leakage Current in Transformer-Less PV Systems.

Considerable current leaks occur if variable frequency voltage pulses are applied to the structure formed by the solar units and the ground [11]. Corrosive damage sustained by the thin film units is usually observed if the negative terminal has voltage that exceeds that of the ground. This corrosion damage is caused by oxidation of the cadmium telluride or silicon found in the components. Permanent damage is observed in the electrical conductivity of the system's glass cover, which causes a significant loss of power in the whole system. [12]. As such, the life expectancy of thin film photovoltaic units is considerably reduced. Nevertheless, this type of corrosive damage can easily be averted by proactively grounding the PV units with a negative charge. The integration of an isolation transformer to the inverter that establishes connection to the grid can offer a possible solution to the current leaks and parasitic capacitance.

It is important to note that personal injury can occur if certain conditions are present. Depending on the inverter topology, structure of the photovoltaic array and types of modulation being utilized, moving the surface of the panels can lead to the conduction of strong currents through the human body resulting in shock. As can be observed in in Fig. 8, ground current ( $\left.\mathrm{I}_{\mathrm{G}-\mathrm{PV}}\right)$ that flows through the PC of the photovoltaic structure can be identified by the dotted line.

A number of recommendations are given, which if applied correctly can lead to a reduction in the incidence of leakage current:

- Grounding the frame of the Photovoltaic group diminishes the capacitance, and in so doing lessening the ground leakage.

- Judiciously selecting the topology and the types of modulation to be applied can lead to a reduction in the voltage fluctuations experienced by the PV structure and ground.

- Disengaging the inverter unit while undergoing maintenance.

The VDE-0126-1-1 suggests the use of a RCM unit in order to guarantee the safe operation of any Photovoltaic system array linked openly to the power grid.

\section{Conclusion}

The importance of PV based power generation system with development of novel inverter structures are presented in this study. An overview about grid-connected PV inverters is presented, focusing on transformerless inverters and related security problems. It's concluded that a typical transformerless PV system diminishes the weight, size, and cost and installation complication of the complete PV system. A detailed investigation of parasitic capacitance of PV arrays and leakage current is required in future.

\section{References}

[1] W. Kleinkauf, G. Cramer, and M. Ibrahim, "PV Systems Technology: State of the Art Developments and Trends in Remote Electrification", SMA Technologies AG, Dec. 2005.

[2] M. Abella and F. Chenlo, "Choosing the Right Inverter for Grid Connected PV Systems", Renewable Energy World, vol. 7, no. 2, pp. 132-147, Mar-Apr. 2004.
[3] S. Kjær, J. Pedersen, and F. Blaabjerg, "A Review of Single Phase Grid Connected Inverters for Photovoltaic Modules", IEEE Transactions on Industry Applications, vol. 41, no. 5, pp. 1292- 1306, Sep. 2005. https://doi.org/10.1109/TIA.2005.853371.

[4] J.M. Carrasco et al. "Power Electronic Systems for the Grid Integration of Renewable Energy Sources: A Survey", IEEE Transactions on Industrial Electronics, vol. 53, no. 4, pp. 1002-1016, Aug. 2006. https://doi.org/10.1109/TIE.2006.878356.

[5] M. Meinhardt and G. Cramer, "Multi String Converter: The Next Step in Evolution of String Converter Technology", European Power Electronics Conference, 2001.

[6] S. Rollier, B. Richard, and M. Keller, "Earth Leakage Control in Solar Inverters", Power System Design Europe, May 2005.

[7] T. Ishikawa "Grid Connected Photovoltaic Power Systems: Survey of Inverter and Related Protection Equipments", Report IEA PVPS T5-05: 2002, 2006

[8] L. Gertmar, P. Karlsson, and O. Samuelsson, "DC Injection to AC Grids from Distributed Generation", European Conference on Power Electronics and Applications, 11-14, pp. 1-10, Sep. 2005. https://doi.org/10.1109/EPE.2005.219420.

[9] H. Häberlin, L. Borgna, M. Kaempfer, and U. Zwahlen, "New Tests at Grid Connected PV Inverters: Overview over Test Results and Measured Values of Total Efficiency", European Photovoltaic Solar Energy Conference, 4-8 Sep. 2006.

[10] S. Jain and V. Agarwal, "A Single Stage Grid Connected Inverter Topology for Solar PV Systems With Maximum Power Point Tracking", IEEE Transactions on Power Electronics, vol. 22, no. 5, pp. 1928-1940, Sep. 2007. https://doi.org/10.1109/TPEL.2007.904202.

[11] O. Lopez, R. Teodorescu, and J. Doval Gandoy, "Multilevel Transformerless Topologies for Single Phase Grid Connected Converters", IEEE Annual Conference on Industrial Electronics, pp. 5191 5196, 2006. https://doi.org/10.1109/IECON.2006.347656.

[12] U. Boeke and H. van der Broeck, "Transformerless Converter Concept for a Grid Connection of Thin film Photovoltaic Modules", IEEE Industrial Application Social Annual Meeting, pp.1-8, Oct. 5-9 2008.

[13] Eisner Safety Consultants "Leakage Current (Part 1)" May 2002.

[14] IEEE Std 1547.1-2005. IEEE Standard Conformance Test Procedures for Equipment Interconnecting Distributed Resources with Electric Power Systems.

[15] IEEE 929-2000. Recommended Practice for Utility Interface of Photovoltaic (PV) Systems.

[16] IEC 61727 "Characteristics of the Utility Interface for Photovoltaic (PV) systems" International Electro technical Commission, IEC 61727,2002

[17] BS EN 61000-3-2. (2001) Electromagnetic Compatibility - Part 32: Limits - Limits for Harmonic Current Emissions (equipment input current up to $16 \mathrm{~A}$ per phase).

[18] Holger Jedtberg,, Alberto Pigazo, Marco Liserre, and Giampaolo Buticchi "Analysis of the Robustness of Transformerless PV Inverter Topologies to the Choice of Power Devices" IEEE Transactions on Power Electronics, Vol. 32, No. 7, July 2017. https://doi.org/10.1109/TPEL.2016.2612888.

[19] Monirul Islam and Saad Mekhilef "Efficient Transformerless MOSFET Inverter for a Grid-Tied Photovoltaic System" IEEE Transactions on Power Electronics, Vol. 31, No. 9, September 2016. https://doi.org/10.1109/TPEL.2015.2501022. 